\title{
Mendelian Susceptibility to Mycobacterial Disease: A Clinical and Laboratory Approach
}

Sagar Bhattad

\begin{abstract}
Mendelian susceptibility to mycobacterial disease (MSMD) is a group of rare genetic disorders characterized by increased susceptibility to infections with low-virulent mycobacteria like the Bacillus Calmette-Guérin (BCG) vaccines and the nontubercular environmental mycobacteria. These patients are also at increased risk of infections with non-typhoidal Salmonella, Candida, and Mycobacterium tuberculosis. In this article, we provide a clinical and laboratory approach to the diagnosis of MSMD. Various genetic defects causing MSMD and their treatment have been discussed.
\end{abstract}

Keywords: Disseminated BCG infection, Interferon, Mycobacterial disease.

Pediatric Infectious Disease (2019): 10.5005/jp-journals-10081-1108

\section{INTRODUCTION}

Mendelian susceptibility to mycobacterial disease (MSMD) is a group of genetic disorders characterized by a defect in interferon $\gamma$ (IFN $\gamma$ )-mediated immunity, leading to a predisposition to atypical and low virulent mycobacteria. The term MSMD is a misnomer, as these patients are not only susceptible to mycobacterial infections but are at increased risk for infections with other intramacrophagic bacteria including Salmonella, Listeria, Klebsiella, and others. These diseases are characterized by a defect in interferon $\gamma$ (IFN $\gamma$ ) production or response to IFN $\gamma$.

\section{IFN $\gamma /$ IL-12 Pathway}

It is essential to understand the functioning of the IFN $\gamma /$ IL-12 pathway in healthy individuals before we discuss MSMD and its defects.

When macrophages engulf microorganisms, they produce IL-12. IL-12 is a heterodimer of IL-12B (p40 subunit) and IL-12A (p35 subunit). p40 subunit is common for IL-12 and IL-23. IL-12 acts on $\mathrm{T}$ and NK cells through its receptor IL-12R. IL-12R is a heterodimer composed of IL-12R $\gamma 1$ and IL-12R $\gamma 2$. Intracellular signaling through IL-12R is mediated by STAT-4 phosphorylation and results in IFN $\gamma$ production. IFN $\gamma$ stimulates macrophages and mediates intracellular killing of microorganisms. IFN $\gamma$ acts via IFN $\gamma$ receptor composed of IFN $\gamma \mathrm{R} 1$ and IFN $\gamma \mathrm{R} 2$. When IFN $\gamma$ acts on IFN $\gamma \mathrm{R} 1$, it facilitates IFN $\gamma R$ 1 dimerization. Following this, ${ }^{2}$ IFN $\gamma R 2$ molecules join this complex. Intracellular signaling is mediated by STAT1 phosphorylation, which translocates to the nucleus and activated IFN $\gamma$ genes. This results in the activation of macrophages and the killing of microbes within them. This has been schematically represented in Figure 1.

An inability to handle intracellular pathogens due to defects in IFN $\gamma$ production (IL-12B, IL-12R $\gamma 1$, IL-12R $\gamma 2$ ) or response (IFN $\gamma R 1$, IFN $\gamma$ R2, STAT1) result in MSMD.

\section{Types of MSMD}

MSMD has been classified based on Table 1 as:

- Pattern of inheritance-AR, $A D, X R$

- Functional impairment (based on residual response to stimulation of receptor)-complete deficiency, partial deficiency - Surface expression of protein-absent, reduced, increased.
Consultant

Division of Pediatric Immunology and Rheumatology, Department of Pediatrics, Aster CMI Hospital, Bangaluru, Karnataka, India

Corresponding Author: Sagar Bhattad, Consultant, Division of Pediatric Immunology and Rheumatology, Department of Pediatrics, Aster CMI Hospital, Bangaluru, Karnataka, India, e-mail: drsagarbhattad@gmail. com

How to cite this article: Bhattad S. Mendelian Susceptibility to Mycobacterial Disease: A Clinical and Laboratory Approach. Pediatr Inf Dis 2019;1(1):34-36.

Source of support: Nil

Conflict of interest: None

\section{IFN $\gamma$ R1 Deficiency}

AR complete IFN $\gamma R 1$ deficiency is the first genetic etiology of MSMD to be identified at the molecular level in $19966^{2,3}$ Patients have the severe clinical phenotype, and present with severe and fatal mycobacterial infections in early childhood. BCG and environmental mycobacteria (EM) (e.g., Mycobacterium fortuitum, Mycobacterium chelonae, Mycobacterium scrofulaceum, etc) have been reported in these patients. Salmonellosis occurs in less than $5 \%$ of children with this deficiency. There is no role of Interferon $y$ injections and hematopoietic stem cell transplant (HSCT) is the treatment of choice. $^{1,4}$

AR partial IFN $\gamma R$ 1 deficiency is a milder disease and cells of these patients show residual response to higher concentrations of IFN $\gamma$. They are susceptible to BCG and environmental mycobacteria but respond well to antitubercular drugs. Interferon $\gamma$ injections are useful in this condition, and HSCT is not recommended.

$A D$ partial IFNYR1 deficiency is characterized by increased expression of receptors on the cell surface due to a defect in the recycling of these receptors. Osteomyelitis caused by atypical mycobacteria is peculiar to this disease, and all patients presenting with mycobacterial osteomyelitis must be investigated for MSMD. ${ }^{4,5}$

\section{IFN $\gamma$ R2 Deficiency}

IFN $\gamma$ R2 deficiency is a rare cause of MSMD. It is inherited in AR form. Complete and partial forms have been noted based on

(O) The Author(s). 2019 Open Access This article is distributed under the terms of the Creative Commons Attribution 4.0 International License (https://creativecommons. org/licenses/by-nc/4.0/), which permits unrestricted use, distribution, and non-commercial reproduction in any medium, provided you give appropriate credit to the original author(s) and the source, provide a link to the Creative Commons license, and indicate if changes were made. The Creative Commons Public Domain Dedication waiver (http://creativecommons.org/publicdomain/zero/1.0/) applies to the data made available in this article, unless otherwise stated. 


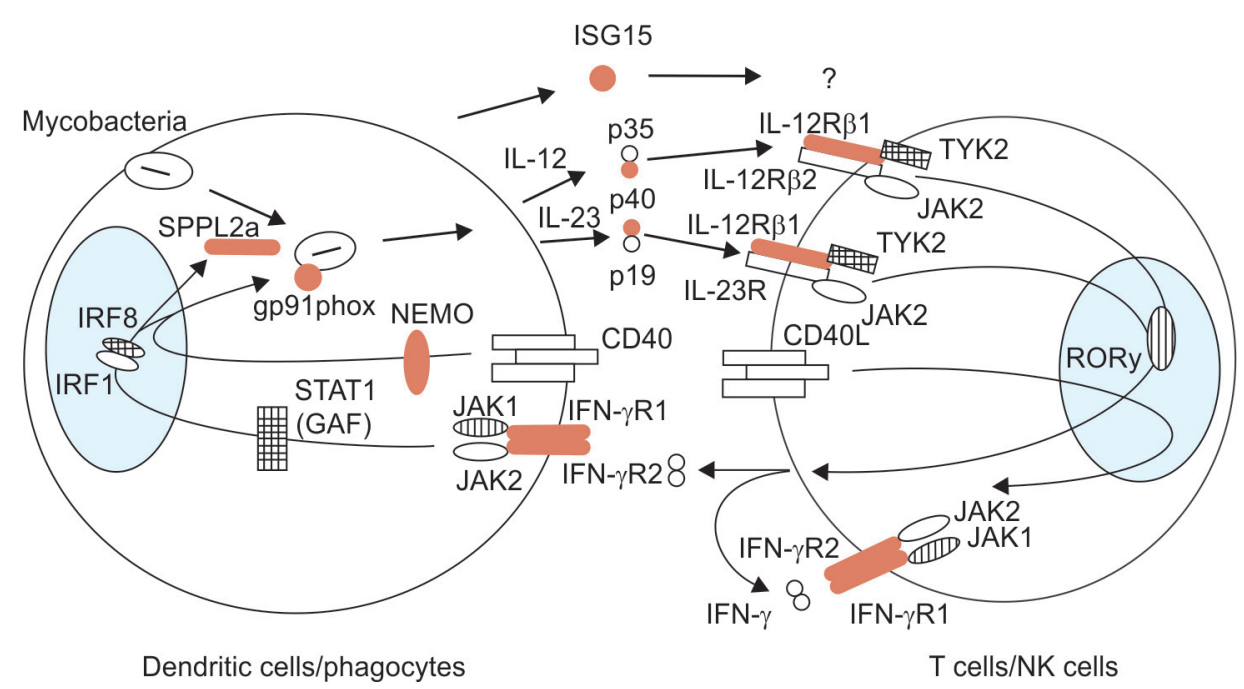

Fig. 1: Critical pathways in controlling mycobacterial infection

Table 1: Brief outline of the common defects causing MSMD

\begin{tabular}{|c|c|c|c|c|}
\hline & $\begin{array}{l}\text { Inheri } \\
\text { tance }\end{array}$ & $\begin{array}{l}\text { Functional } \\
\text { impairment }\end{array}$ & $\begin{array}{l}\text { Protein } \\
\text { expression }\end{array}$ & $\begin{array}{l}\text { Clinical } \\
\text { phenotype }\end{array}$ \\
\hline $\begin{array}{l}\text { Complete } \\
\text { IFN } \gamma \mathrm{R} 1 \\
\text { deficiency }\end{array}$ & $A R$ & Complete & No & Severe \\
\hline $\begin{array}{l}\text { Complete } \\
\text { IFN } \gamma \mathrm{R} 1 \\
\text { deficiency }\end{array}$ & $\mathrm{AR}$ & Complete & Yes* $^{*}$ & Severe \\
\hline $\begin{array}{l}\text { Partial } \\
\text { IFN } \gamma \text { R1 } \\
\text { deficiency }\end{array}$ & $\mathrm{AR}$ & Partial & Yes & Mild \\
\hline $\begin{array}{l}\text { Partial } \\
\text { IFN } \gamma \text { R1 } \\
\text { deficiency }\end{array}$ & $A D$ & Partial & Yes & Mild \\
\hline $\begin{array}{l}\text { Complete } \\
\text { IFN } \gamma \text { R2 } \\
\text { deficiency }\end{array}$ & $A R$ & Complete & No & Severe \\
\hline $\begin{array}{l}\text { Complete } \\
\text { IFN } \gamma \text { R2 } \\
\text { deficiency }\end{array}$ & $\mathrm{AR}$ & Complete & Yes* & Severe \\
\hline $\begin{array}{l}\text { Partial } \\
\text { IFN } \gamma \text { R2 } \\
\text { deficiency }\end{array}$ & $A R$ & Partial & Yes & Mild \\
\hline $\begin{array}{l}\text { IL-12Ry1 } \\
\text { deficiency }\end{array}$ & AR & Complete & No & Variable \\
\hline $\begin{array}{l}\text { IL-12B } \\
\text { deficiency }\end{array}$ & $A R$ & Complete & No & Variable \\
\hline $\begin{array}{l}\text { Stat1 } \\
\text { deficiency }\end{array}$ & $A D$ & Partial & Yes & Mild \\
\hline $\begin{array}{l}\text { NEMO } \\
\text { defect }\end{array}$ & $\mathrm{XR}$ & Partial & Yes & Variable \\
\hline
\end{tabular}

*Dysfunctional protein, Increased expression

cellular response to IFN $\gamma$. Some of these mutations are gain of glycosylation defects. ${ }^{6}$ Clinically, complete IFN $\gamma$ R2 deficiency resembles the complete IFN $\gamma \mathrm{R} 1$ deficiency and has a severe clinical phenotype. Patients are at risk of infections with BCG and EM (M. avium, M. fortuitum) and carry a poor prognosis. HSCT is the treatment of choice. Partial IFN $\gamma R 2$ deficiency is a milder form of the disease and only a handful of cases have been reported to date. These patients do well on interferon $\gamma$ injections.

\section{IL-12R $\gamma$ and IL-12B Deficiency}

Both IL-12 and IL-23 contain p40 subunit (encoded by IL-12B gene) and IL-12Ry 1 chain is present in IL-12R and IL-23R. Thus, mutations in the IL-12B gene or IL-12Ry1 chain impair the functions of both these cytokines. Patients with IL-12B and IL12Ry deficiency are at increased risk of BCG disease and salmonellosis caused by nontyphoidal Salmonella. Salmonellosis is noted in more than $50 \%$ of these patients, and the higher incidence of Salmonella infection in patients with an impaired IL-12/IL-23 pathway than in patients with an impaired IFN $\gamma$ pathway suggests that IL-12 and IL-23 may play a particular role in controlling Salmonella infection via IFN $\gamma$ independent mechanisms (Fig. 1).

AR complete IL-12Ry1 deficiency is the most common cause of MSMD. The clinical phenotype of this disease is very heterogeneous, ranging from early death in infancy to an asymptomatic course throughout adulthood. Mycobacterial infections are the most frequent infections observed in these patients (BCG), M. avium, M. avium intracellulare complex, M. chelonae, M. fortuitum, M. fortuitum-chelonae complex, M. genevense, M. gordonae, M. tilburgii, M. triplex, $M$. simiae). The prognosis of this immunodeficiency is variable, but good in most cases. Patients should be treated with prolonged and aggressive antibiotics against mycobacteria in addition to subcutaneous IFN $\gamma$. HSCT is not indicated in most of the cases. ${ }^{7}$

AR complete IL-12B deficiency has a clinical presentation similar to IL-12R $\gamma 1$ deficiency. These children present with BCG disease and recurrent salmonellosis. The clinical course is variable, though most patients do well on antibiotics and IFN $\gamma$ therapy.

\section{X-linked Recessive NEMO Deficiency}

NEMO deficiency is typically associated with incontinentia pigmenta (X-linked dominant inheritance) and anhidrotic ectodermal dysplasia with immunodeficiency (EDA-ID) due to null and hypomorphic mutations, respectively. The E315A and R319Q mutations of NEMO, cause MSMD, wherein patients are at increased risk for atypical mycobacterial infections, especially M. avium. ${ }^{8}$ Prognosis is variable, and most reported patients have done well on IFN $\gamma$ injections. 


\section{Rarer causes of MSMD}

AR ISG15 deficiency, AD IRF8 deficiency, AD STAT1 deficiency, AR SPPL2A deficiency, AR TYK2 deficiency, and XR CYBB deficiency are rare causes of MSMD. The available literature is based on a few case studies. ${ }^{1,8}$

\section{Syndromic MSMD}

It is typically defined as a combination of both mycobacterial disease and other infections associated with a more complex cellular phenotype. AR STAT1 and TYK2 deficiencies, AD GATA2 deficiency, and recently described RORY/RORYT and JAK1 deficiencies present with syndromic MSMD. These patients are characterized by atypical mycobacterial infections, viral infections, chronic mucocutaneous candidiasis, and other abnormalities. ${ }^{9}$

\section{When should one think of MSMD?}

- Disseminated BCG infection

- Infections with environmental mycobacteria

- Recurrent salmonellosis (caused by non-typhoidal salmonella)

- Osteomyelitis caused by atypical mycobacteria

- Infections with intracellular organisms-mycobacteria, virus, fungi (candida)

- With normal immunological screen (immunoglobulins, lymphocyte subsets, and tests for the chronic granulomatous disease being normal).

\section{Laboratory Approach}

\section{Flow Cytometry for Protein Expression}

IL-12R $\gamma 1$ and IFN $\gamma \mathrm{R} 1$ protein expression can be studied by flow cytometry. Absent IL-12R $\gamma 1$ expression on T cells is diagnostic of IL-12R $\gamma 1$ deficiency with a sensitivity of $95 \%$. AR complete IFN $\gamma \mathrm{R} 1$ deficiency is characterized by absent protein expression while increased expression is noted in AD variety, due to defective recycling of receptors.

\section{Flow Cytometry for Evaluation of Pathways}

Study of pathways involved in IL-12 and INFy signaling can provide a clue to the underlying defect. Using flow cytometry, one can study phosphorylated STAT1 after IFN $\gamma$ stimulation and phosphorylatedSTAT4 by IL-12 stimulation. Decreased STAT1 phosphorylation would suggest that there is a possible defect in either STAT1, IFN $\gamma$ R1 or IFN $\gamma$ R2. Decreased STAT4 phosphorylation can occur in cases of IL-12 receptor deficiency.
Functional studies may be carried out in research laboratories by evaluating the response to INF $\gamma$ and patients can be classified into complete and partial deficiencies. This would have an implication in their clinical management.

Genetic studies can be done by next-generation sequencing technology and confirmed by Sanger sequencing.

\section{Conclusion}

Children and adults with disseminated BCG infection and infections with atypical mycobacteria must be evaluated for MSMD. These patients are also predisposed to salmonellosis and other intracellular pathogens. AR complete IFN $\gamma$ deficiency (IFN $\gamma$ R1 and R2) present with severe infections in early childhood and warrant HSCT. Partial IFN $\gamma$ R1 and R2 deficiencies have milder phenotype and can be managed with IFN $\gamma$ injections. IL12R $\gamma 1$ deficiency is the most common cause of MSMD and has a variable clinical course. With the advancement of molecular genetics, newer causes of MSMD are being increasingly recognized.

\section{References}

1. Bustamante J, Boisson-Dupuis S, Abel L, et al. Mendelian susceptibility to mycobacterial disease: genetic, immunological, and clinical features of inborn errors of IFN-gamma immunity. Semin Immunol 2014;26:454-470.

2. Jouanguy $E$, Altare F, Lamhamedi S, et al. Interferon-gamma-receptor deficiency in an infant with fatal bacille Calmette-Guerin infection. N Engl J Med 1996;335:1956-1961.

3. Newport MJ, Huxley CM, Huston S, et al. A mutation in the interferongamma-receptor gene and susceptibility to mycobacterial infection. N Engl J Med 1996;335:1941-1949.

4. Dorman SE, Picard C, Lammas D, et al. Clinical features of dominant and recessive interferon gamma receptor 1 deficiencies. Lancet 2004; 364(9451):2113-2121.

5. Obinata K, Lee T, Niizuma T, et al. Two cases of partial dominant interferon- $\gamma$ receptor 1 deficiency that presented with different clinical courses of bacille Calmette-Guérin multiple osteomyelitis. J Infect Chemother 2013;19(4):757-760

6. Vogt G, Chapgier A, Yang K, Chuzhanova N, et al. Gains of glycosylation comprise an unexpectedly large group of pathogenic mutations. Nat Genet 2005;37:692-700

7. de Beaucoudrey L, Samarina A, Bustamante J, et al. Revisiting human IL-12Rbeta1 deficiency: a survey of 141 patients from 30 countries. Medicine (Baltimore) 2010;89(6):381-402

8. Filipe-Santos $\mathrm{O}$, Bustamante J, Haverkamp MH, et al. X-linked susceptibility to mycobacteria is caused by mutation in NEMO impairing CD40-dependent IL-12 production. J Exp Med 2006;203(7):1745-1759

9. Rosain J, Kong XF, Martinez-Barricarte R, Oleaga-Quintas C, et al. Mendelian susceptibility to mycobacterial disease: 2014-2018 update. Immunol Cell Biol 2018 Sep 28. 